\title{
KOMODIFIKASI SEKSUAL DALAM KEPENTINGAN EKONOMI PORTAL BERITA ONLINE
}

\author{
Dani Fadillah \\ Jurusan Ilmu Komunikasi, FSBK Universitas Ahmad Dahlan, Yogyakarta \\ daniuad@yahoo.co.id
}

\begin{abstract}
Press entered a new era. It is characterized by developing online media. By nature papperless online media to be more efficient in operation. To disseminate content that they are prepared, generally the online media managers utilizing social media such as facebook, twitter, or etc. But not only leave it there, the content is spread also equipped with something that is able to attract the reader's attention. Even able to make the social media users who happen to view such content terpersuasi to click on the content. Generally seasoning the attention it is the things that are controversial (that it contains elements of sexuality). There has been a sexual commodification process undertaken by several online news portals to get as visitors. It confirms Marx and Mosco of commodification as a change of the exchange rate.
\end{abstract}

\begin{abstract}
Abstrak
Dunia pers memasuki era baru. Hal ini ditandai dengan berkembangkan media online. Dengan sifatnya yang papperless media online lebih hemat dalam pengoperasiannya. Dalam proses menyebarluaskan konten-konten yang mereka siapkan, umumnya para pengelola media online memanfaatkan media sosial seperti facebook, twitter, atau yang sejenisnya. Namun, konten yang disebarkan turut dibekali dengan sesuatu yang mampu menarik perhatian pembaca. Bahkan mampu membuat para pengguna media sosial yang kebetulan melihat konten tersebut terpengaruh untuk melihat konten tersebut. Umumnya bumbu penarik perhatian itu adalah hal-hal yang sifatnya kontroversi (mengandung unsur seksualitas). Telah terjadi proses komodifikasi seksual yang dilakukan oleh beberapa portal berita online untuk mendapatkan pengunjung sebanyak-banyaknya. Hal ini membenarkan pernyataan Marx dan Mosco tentang komodifikasi sebagai perubahan dari nilai tukar.
\end{abstract}

Keywords: Commodification, Online Media, Sexuality 


\section{PENDAHULUAN}

Saat ini dunia online sudah bukanlah sebuah dunia yang asing bagi masyarakat kita, dunia online menjadi sebuah keniscayaan seiring dengan proses digitalisasi dan konvergensi media yang senantiasa terjadi di tenhag-tengah kita. Mulai dari percakapan biasa hingga hal-hal yang bersifat transaksional berlangsung dalam dunia virtual tersebut. Bahkan konon meski jasad manusia ada dalam dunia nyata, namun manusia lebih banyak menghabiskan waktunya dalam dunia maya.

Melihat fenomena tersebut, para pelaku bisnisdalamduniausahapunmulaimerambah dunia maya untuk mempromosikan apa yang mereka hasilkan. Pun demikian dengan perusahaan berita (pers), tidak cukup yang tadinya mereka sudah mendigitalisasikan media cetaknya dalam bentuk portal digital, mereka pun memanfaatkan media sosial untuk mempublikasikannya agar terlihat oleh mayarakat yang sedang berselancar dalam dunia maya.

Untuk menyebarluaskan kontenkonten yang mereka siapkan, umumnya para pengelola media online memanfaatkan media sosial seperti facebook, twitter, atau yang sejenisnya. Namun tidak hanya cukup sampai disitu saja, konten yang disebarkan turut dibekali dengan sesuatu yang mampu menarik perhatian pembaca bahkan mampu membuat para pengguna media sosial yang kebetulanmelihatkontentersebutterpersuasi untuk meng-klik konten tersebut.

Umumnya bumbu penarik perhatian itu adalah hal-hal yang sifatnya kontroversi baik berupa gambar mau pun bahasa yang digunakan sebagai judul, dan tidak sedikit dari gambar mau pun bahasa kontroversi yang digunakan itu mengandung unsur seksualitas.

Pemaparan di atas jelas menunjukan bagaimana telah terjadi proses komodifikasi terhadap hal-hal yang berbau seksualitas yang dilakukan oleh penyedia portal media online guna menarik perhatian masyarakat yang sedang berselancar di dunia maya untuk masuk dalam portal yang disediakan. Proses komodifikasi yang dilakukan oleh penyedia portal media online itu dapat dibongkar melalui perspektif ekonomi politik media.

\section{TINJAUAN TEORI}

\section{Ekonomi Politik Media}

Pada bagian ini penulis mencoba melihat bagaimana perspektif ekonomi politik bekerja dalam membongkar upayaupaya kapitalisme dalam menghegemoni masyarakat lewat berbagai siaran dan acara dalam media. Sehingga ada ketimpangan serta ketidakadilan dalam proses tersebut.

Pengertian ekonomi politik menurut Vincent Mosco (1996: 25-38) ada dua macam, yaitu sempit dan luas. Dalam pengertian sempit artinya adalah kajian dalm ranah relasi sosial, spesifiknya lagi relasi dalam hal kekuasaan membentuk produksi, distribusi dan konsumsi sumber daya. Dalam sumber daya ini termasuk di dalamnya produkproduk komunikasi semacam surat kabar, buku, video, dan film untuk khalayak.

Dalam pengertian luas masuk dalam ranah kajian mengenai kontrol dan pertahanan kehidupan sosial. Kontrol di sini secara spesifik berperan dalam pengaturan individu dan anggota kelompok secara internal, dimana supaya dapat bertahan mereka harus memproduksi sesuatu yang dibutuhkan agar dapat mereproduksi kembali diri mereka sendiri. Proses kontrol ini otomatis akan bersifat politis, disebabkan ketika proses tersebut berlangsung akan melibatkan pengorganisasian sosial hubungan-hubungan dalam sebuah komunitas. Dan pada dasarnya, proses bertahan (survival processes) akan bersifat ekonomis, sebab berhubungan dengan persoalan produksi dan reproduksi.

Disamping itu, Denis McQuail (1994: 68) juga menjelaskan bahwa pendekatan ekonomi politikini lebihbanyakmemusatkan perhatian pada struktur ekonomi dari pada muatan isi ideologis media. Sehingga ideologi memiliki ketergantungan pada kekuatan ekonomi dan mengarahkan perhatian pada struktur kepemilikan dan mekanisme kerja kekuatan market media. Dalam hal ini media juga menjadi bagian dari sistem ekonomi 
yang secara otomatis memiliki hubungan yang akrab dengan sistem politik.

Oleh karena pengertian itulah maka tidak keliru jika kemudian Barker (2009: 295) mengatakan bahwa ekonomi politik tidak dapat melepaskan diri dari keterkaitannya dengan kekuasaan yang dibarengi distribusi sumber daya ekonomi dan sumber daya sosial. Artinya suatu persoalan yang terkait dengan siapa yang memiliki dan menguasai produksi dan mekanisme distribusi media, bersama dengan konsekuensi-konsekuensi pola-pola kepemilikan dan pengendalian bagi kosntruksi soasial kultural.

Dan jika diusut kembali muasalnya, ekonomi politik sebenarnya sama seperti Marxisme klasik yang menyalahkan kekuasaan-kepemilikan modal (media) atas efek buruk yang timbul bagi masyarakat yang timbul dari sang pemilik modal. Dalam pemahaman ini, isi media adalah komoditas utama untuk dijual di pasar, dan isi pesan yang disampaikan oleh media akan diatur oleh apa yag akan diambil oleh pasar. Sistem ini mengacu pada sistem konservatif dengan menjadikan jenis progam tertentu dan saluran media tertentu menjadi sangat dominan sampai meminggirkan program dan saluran media yang lain (Littlejohn, 2009: 432).

Agus Sudibyo (2004: 7) sendiri membaca pendekatan ekonomi-politik media memiliki ciri sentral yang penting, yaitu; pendekatan ekonomi politik bersifat holistik. Artinya ada interelasi secara menyulur antara dinamika sosial, politik dan budaya dalam suatu masyarakat, serta menghindari kecenderungan untuk mengabstrasikan realitas-realitas sosial ke dalam teori ekonomi atau teori politik. Media pertama-tama harus diletakkan dalam totalitas sistem yang lebih luas,sebagaibagianintregaldariproses-proses sosial memproduksi dan mengonsumsi teks, baik pada jenjang organisasi, industri dam masyarakat, serta pendekatan kritis ekonomi politik media bersifat historis. Menjelaskan secara memadai perubahan-perubahan dan dialektika yang terjadi berkaitan dengan posisi dan peranan media komunikasi dalam sistem kapitalisme global.
Menyempurnakan ciri sentral diatas, Vincent Mosco (2009: 13) merumuskan tiga karakter tambahan studi ekonomi politik, yaitu; realis, inklusif, dan kritis. Realisme membuat ekonomi-politik kritis sangat menghindari ketergantungan eksklusif terhadap teori abstrak atau deskripsi empiris. Kemudian inklusif berasal dari watak tentang kesadaran bahwa kehidupan sosial tidak dapat dirangkum ke dalam satu teori. Tidak ada pendekatan yang paling tepat dan paling ideal dalam studi ekonomi-politik komunikasi. Studi ekonomi-politik sangat terbuka terhadap perdebatan-perdebatan multi-perspektif dan lintas disiplin. Lalu kritis okonomi-politik mewujud pada kepekaan terhadap berbagai bentuk ketimpangan dan ketidakadilan. Ekonomipolitik memberi perhatian besar terhadap faktor-faktor ideologis dan politis yang pengaruhnya bersifat berkelanjutan terhadap suatu masyarakat.

Sudut pandang ekonomi politik secara lugas dapat membongkar berbagai kejahatan sosial yang dilakukan oleh media terhadap masyarakat, karena media saat ini telah menghambakan diri pada kepentingan pasar dari pada kepentingan para penontonnya. Media selalu menjadikan acara-acara kesukaan penontonnya (dalam hal ini hal-hal yang berkaitan dengan seksualitas) sebagai komoditas yang dijualbelikan kepada para pengiklan agar memperoleh keuntungan profit kapital. Dalam kajian ekonomi politik media, ini minimal masyarakat mengetahui bahwa tidak semua media saat ini murni sebagai sosok agung yang memberi petunjuk bagi umat manusia, namun telah berubah menjadi setan kapitalisme yang rakus.

\section{Komodifikasi}

Menyaksikan wall atau timeline dalam media sosial ibarat terpaan tsunami yang tiada hentinya. Hal ini yang membuat kapitalisme begitu bersemangat umtuk melakukan promosi besar-besaran atau menarik masyarakat untuk masuk dalam portal yang telah disediakannya dengan berbagai jebakan yang dianggap dapat 
menarik, dan kerap kita jumpai hal-hal yang dianggap paling menarik untuk menjebak para peselancar dunia maya adalah dengan menyediakan konten-konten yang berbau seksualitas. Singkat cerita seksualitas tak bisa lepas dari proses komodifikasi.

Komodifikasi sendiri oleh Karl Marx disebut telah menjadikan segala hal bisa saling diukur dalam dua buah buku 'sama nilainya' dengan satu jas, sayangnya, memiliki harganya sendiri. Masyarakat borjuis, singkatnya mereduksi nilai kemanusiaan menjadi nilai ekonomis dan mereka menyeragamkan berbagai perbedaan yang mestinya menjadi karakteristik kehidupan sehari-hari (Beilhartz, 2005: 275).

Penjelasan Karl Marx tentang komodifikasi ini semakin mempertegas bahwa berbagai elemen seksualitas mampu dipertukarkan untuk dijadikan sebuah nlai ekonomis yang mempunyai nilai jual yang sangat tinggi. Salah satu elemen seksualitas yang mengalami komodifikasi adalah tubuh dan kata-kata yang bersifat vulgar.

Tak jarang hal-hal yang berbau seksualitas itu berusaha untuk diparalelkan dengan tokoh tertentu yang memiliki banyak penggemar. Menurut Joli Jenson (1992), literatur mengenai kelompok penggemar dihantuiolehcitrapenyimpangan. Penggemar selalu dicirikan (mengacu pada asal usul istilahnya) sebagai suatu kefanatikan yang potensial. Hal ini berarti bahwa kelompok penggemar dilihat sebagai perilaku yang berlebihan dan berdekatan dengan kegilaan. Jenson menunjukkan dua tipe khas patologi penggemar, individu yang terobsesi (biasanya laki-laki) dan kerumunan histeris (biasanya perempuan) (John Storey, 2008: 157).

Beberapacirikhasdaripenggemarseperti fanatik, terobsesi dan histeris inilah yang dijadikan oleh kapitalis untuk melakukan komodifikasi yang bersifat seksual dalam portal berita yang mereka sajikan. Sebagai contoh bagimana sebuah portal berita ama menampilkan sebuah berita yang lebih menonjolkan seksualitas dalam bahasa dan gambar yang ditampilkan:
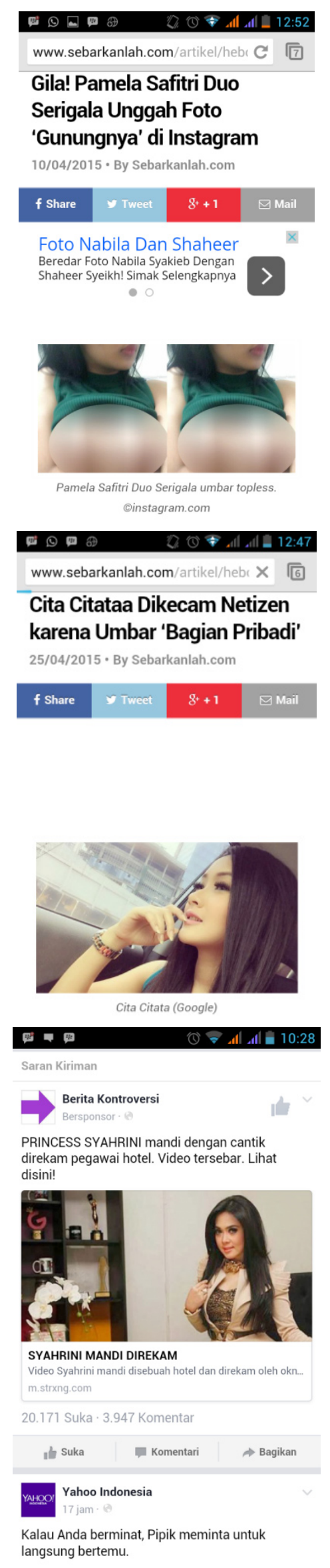

Gambar 1: Seksualitas Artis Sebagai Bahan Komodifikasi 
Dunia selebritis yang memang memiliki banyak penggemar memang menawarkan sesuatu yang menggiurkan bagi kapitalis untuk mendapatkan lahan untuk memasarkan berbagai produknya, sebuah arena 'alami' bagi promosi produk dan mendapatkan audien.

\section{METODE}

Jenis penelitian ini adalah penelitian pustaka (library research). Dalam penelitian pustaka, pengumpulan data-datanya diolah melalui penggalian dan penelusuran atas buku-buku, surat kabar, majalah, jurnal dan catatan lainnya yang memiliki hubungan dan dapat mendukung pemecahan masalah serta pencarian kebenaran dalam penelitian ini.

Pengumpulan data dilakukan denagan metode dokumentasi, yaitu pengumpulan data dengan cara mencari data mengenai hal-hal atau variabel yang berupa catatan, transkip, buku, surat kabar, majalah atau hal lainnya yang memiliki hubungan dengan permasalahan penelitian ini.

Dalam penyusunan tulisan ini, penulis menggunakan beberapa pendekatan, pertama adalah pendekatan historis yakni dengan melacak akar dari korporatokrasi. Kedua adalah pendekatan empiris, yaitu dengan menganalisa realitas obyektif masyarakat dunia saat ini yang dikuasai oleh para korporasi-korporasi. Ketiga adalah pendekatan normatif, yakni dengan mencoba memahami permasalahan korporatokrasi dengan sistem yang diterapkan oleh para kepala negara penentang korporatokrasi.

Data-data yang diperoleh kemudian diklasifikasi dan dikritisi dengan seksama sesuai dengan referensi yang ada. Kemudian dianalisa dengan perspektif gerakan antikorporatokrasi. Data-datayang diperoleh dari berbagai macam sumber akan dianalisa melalui metode: pertama, metode induktif, yaitu metode yang berangkat dari faktafakta khusus, peristiwa-peristiwa kongkrit, kemudian dari fakta tersebut ditarik kesimpulan yang bersifat umum. Metode ini digunakan untuk memperoleh pengertian yang utuh tentang pemahaman topik yang diteliti.

Kedua, metode deduktif, yaitu metode yang berangkat dari pengetahuan atau faktafakta yang bersifat umum untuk menilai pengetahuan yang bersifat khusus. Metode ini digunakan dalam rangka mengetahui tentang detail-detail pemahaman yang ada dalam berbagai macam teks.

Proses analisa ini diawali dengan mendeskripsikan, mempelajari dan menginterpretasikan dengan metodemetode diatas yang diharapkan mampu memberikan kesimpulan yang memadai.

\section{HASIL DAN PEMBAHASAN}

\section{Seksualitas yang Terkomodifikasi}

Seperti yang disampaikan Vincent Mosco (2009: 129) bahwa komodifikasi digambarkan sebagai cara kapitalisme mebawa akumulasi tujuan kapitalnya. Atau dapat pula digambarkan sebagai sebuah perubahan nilai fungsi atau guna menjadi sebuah nilai tukar. Dan sekarang ini telah sangat banyak sekali bentuk komodifikasi yang muncul dalam perkembangan kehidupan manusia.

Dalam kerangka berpikir komodifikasi Mosco, apa yang telah terjadi pada kontenkonten berita yang dimaksud merupakan komodifikasi isi media dan audiens. Bagaimana berita-berita yang memuat gambar dan tulisan serta ulasan yang bernada sama berkali-kali, yang tujuan utamanya adalah untuk menjadikan seksualitas sebagai sesuatu yang dicari-cari dimasyarakat mesku pun ada pula yang tertipu. Sehingga terlihat sekali bagaimana isi atau content dari media menjadi komoditas karena mempunyai nilai jual yang tinggi di mata penonton.

Berikutnya yang menjadi korban komodifikasi adalah audiens atau para peselancar dunia maya. Karena audiens merupakan komoditi paling vital, audienslah yang membuat media memperoleh keuntungan dari iklan, sehingga tiap pengunjung yang terjebak dan memasuki portal yang telah disediakan akan diklaim sebagai pelanggan dan siap dijual pada pengiklan. Bisa dibayangkan berapa jumlah 
masyarakat yang tertarik untuk memasuki sebuah portal yang terluhat memuat unsurinsur seksualitas di dalamnya

\section{Eksploitasi Penonton}

Mengikuti Oscar Gandy, Jr. dalam Tracking the Audience (1990), khalayak mengalami eksploitasi melalui dua cara; Pertama, khalayak dijadikan produk media. Dalam domain ini makin banyak yang terjebak masuk dalm portal yang dimaksud akan meningkatkan rating portal yang bersangkutan. Jika angka rating tinggi maka akan diklaim khalayak yang menjadi pelanggannya juga tinggi. Angka rating itulah yang kemudian dijual kepada pemasang iklan.

Pada konteks itu terciptalah pasar yang dimainkan penyedia portal berita dengan para pengiklan. Artinya penyedia portal berita memperlakukan khalayak sebagaimana layaknya produk (komoditas) dimana pihak yang menjual produk itu adalah sang pemilik portal berita sementara itu, pihak yang menjadi pembelinya adalah para pengiklan.

Produk yang bagus hanya dinilai dari kuantitas (jumlah) penonton. Makin banyak penonton, maka makin mahal pula harga produk itu. Bukan kenyataan yang janggal ketika ada yang terjebak untuk masuk dalam portal yang disangka memuat unsur seksualitas ternyata isinya hanya iklan, atau menyediakan kolom khusus untuk memasang iklan.

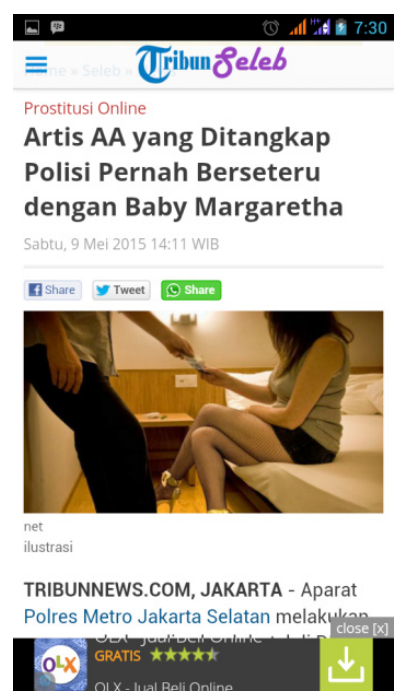

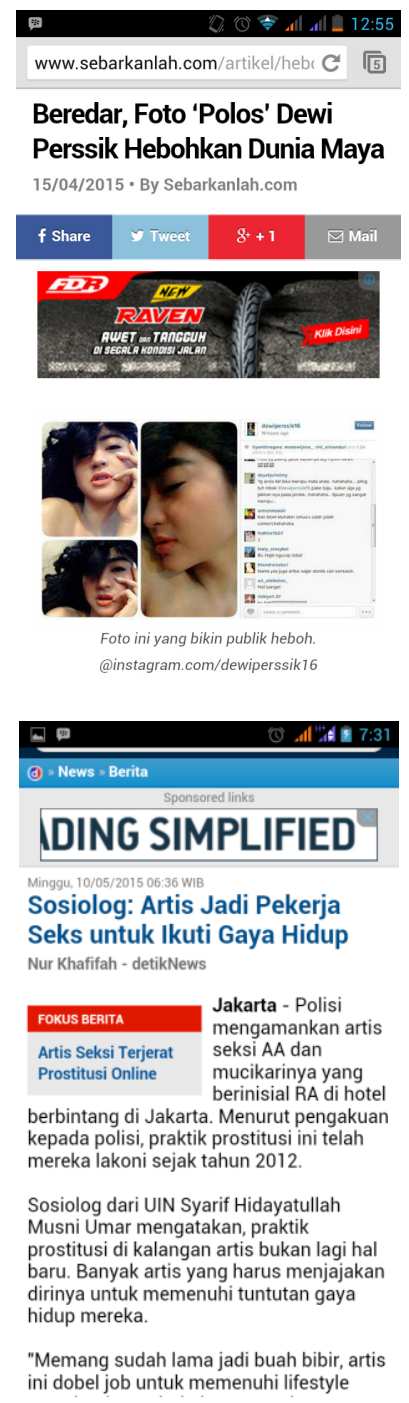

\section{Gambar 2: Iklan dalam Berita Bermuatan Seksualitas}

Makin banyak yang masuk dalam portal maka makin banyak pula iklan berseliweran. Hal ini harus dimaknai bahwa khalayak sebagai produk memang berharga mahal. Realitas tersebut menunjukkan tayangan berbau seksualitas memang banyak yang menyaksikandanmendatangkanpenghasilan yang tinggi bagi pengelola portal.

Kedua, khalayak sebagai pekerja. Dalam domain ini berselancar di dunia maya tidak dapat dianggap sekadar sebagai aktivitas relaksasipsikologisbelaka. Menataplayarkaca yang menyajikan berbagai informasi adalah bekerja. Ketika khalayak diubah menjadi angka-angka rating pada saat bersamaan menunjukkan bagaimana menyaksikan layar komputer atau smartphone dicatat sebagai 
pekerjaan tersendiri. Artinya pemilik portal mengonstruksikan khalayak bukan hanya sebagai penonton, melainkan juga sebagai pekerja.

Bisnis portal media online bukan hanya persoalan ekonomi tayangan, tapi ekonomi khalayak pula. Sebuah portal hanya bisa sukses ketika jumlah pengunjungnya banyak, sebaliknya yang tidak memiliki pengunjung pasti akan rugi. Hal ini dapat diibaratkan dengan pabrik yang mempekerjakan buruh, jika jumlah buruh yang bekerja di pabrik melimpah maka pabrik itu dipandang sukses. Sebaliknya, jika buruh pabrik itu sedikit jumlahnya, bahkan tidak ada sama sekali, maka pabrik itu dipandang gagal.

\section{SIMPULAN}

Melalui pemaparan kali ini dapat disimpulkan bahwa telah terjadi proses komodifikasi seksual yang dilakukan oleh beberapa portal berita online untuk mendapatkan pengunjung sebanyakbanyaknya. Dan melalui perspektif ekonomi politik media semua kepentingan beberapa penyedia portal media online menjadi terungkap, sehingga apa yang dikatakan oleh Marx dan Mosco tentang komodifikasi sebagai perubahan dari nilai tukar terbukti dan menjadi kenyataan pada kasus ini.

Dikemudian hari pastinya akan ada komodifikasi lain yang dilakukan oleh portalportal media online tertentu, karena melalui komdifikasi-lah semua usaha bisa hidup dan berkembangkan. Sedangkan untuk unsur seksualitas sepertinya sudah menjadi bahan penarik perhatian pengunjung yang menjanjikan bagi pasar, sehingga beberapa tahun ke depan akan selalu menjadi komoditas yang menggiurkan.

\section{DAFTAR PUSTAKA}

Barker, Chris. 2009. Cultural Studies, Teoridan Praktik. Yogyakarta: Kreasi Wacana.

Beilharz, Peter. 2005. Teori-Teori Sosial. Yogyakarta: Pustaka Pelajar.

Joli Jensen. 1992. Adoring Audience Fan Culture and Popular Media. London: Routledge.

Littlejohn. 2004. Teori Komunikasi. Jakarta: Salemba Humanika.

McQuail, Denis. 1994. Mass Communication Theory. London: Sage Publications Ltd

Mosco, Vincent. 2009. The Political Economy of Communication Second Edition. London: Sage Publications Lt.

Oscar, Gandy Jr, 1990. 'Tracking the Audience' in Questioning Media: a Critical Introduction. London: Sage Publication

Storey, John. 2010. Cultural Studies dan Kajian Budaya Pop: Pengantar Komprehensif Teori dan Metode. Yogyakarta: Jalasutra. 
